\title{
NICKELHEXAHYDRITE FROM FINLAND
}

\author{
S. Karup-Møller
}

Karup-Møller, S. 1973: Nickelhexahydrite from Finland. Bull. Geol. Soc. Finland 45, 155-158.

Morphological description, spectrographic analyses of minor elements and cell dimensions are given for the nickelhexahydrite from the Lahnaslampi talc deposit in Finland.

S. Karup-Moller, Institute of Petrology, University of Copenhagen, Ø. Voldgade 5-7, Copenbagen, Denmark.

\section{Introduction}

Nickelhexahydrite $\left(\mathrm{NiSO}_{4} \cdot 6 \mathrm{H}_{2} \mathrm{O}\right)$ is well known to the chemist as a synthetie compound. It was first described as a naturally occurring mineral species from the Norilsk No. 1 nickelcopper deposit in the USSR by Oleinikov et. al. (1965). Recently it has been found in the Lahnaslampi talc deposit in eastern Finland where it occurs as rare precipitates forming irregular crust zones up to half a meter in width and several meters in length following shear zones in fine grained talc. The mode of occurrence of the mineral suggests that it was precipitated from nickel-bearing aqueous meteoric solutions when these reached the surface after they had penetrated the underlying ultramafic rocks. The nickel may originally have been tied up in the lattice of the silicates or alternatively it may have been derived from oxidized nickel-bearing sulphides. Although easily dissolved in cold water nickelhexahydrite crystallizes when not exposed to rain. The unusually dry and sunny summer season in Finland in 1972 may have been a significant factor in the formation and preservation of the mineral.

The mode of occurrence of the nickelhexahydrite from Lahnaslampi closely resembles that of the mineral at Norilsk where it was precipitated from the evaporating mine waters at the bottom of the »Severmaya» open pit. The mineral was also found as a crust covering sulphide-bearing gabbro-dolerite belonging to the oxidation zone exposed in the same open pit. Here the mineral was precipitated from acid aqueous solutions which, after having penetrated the oxidation zone, reached the surface and evaporated. The mineral developed during the dry spring and summer seasons only to disappear again during the wet fall.

The mineralogy of the nickelhexahydrite has been described in such detail by Oleinikov et al. (1965) that only a few supplementary observations of interest are given in the following. 


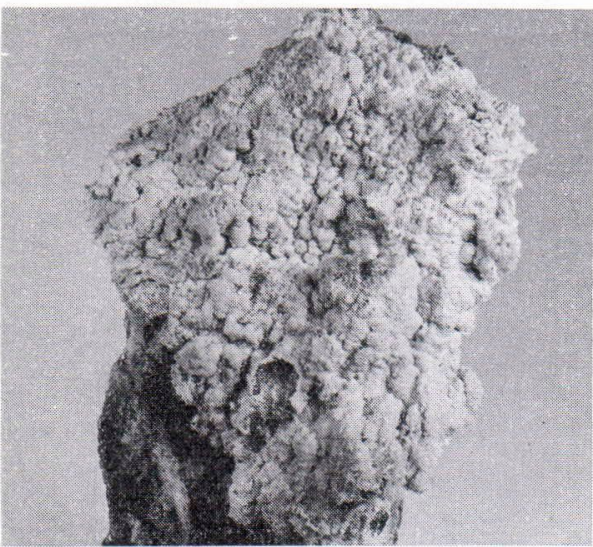

FIG. 1. Very porous, irregular crust of nickelhexahydrite precipitate on talc. (Natural size).

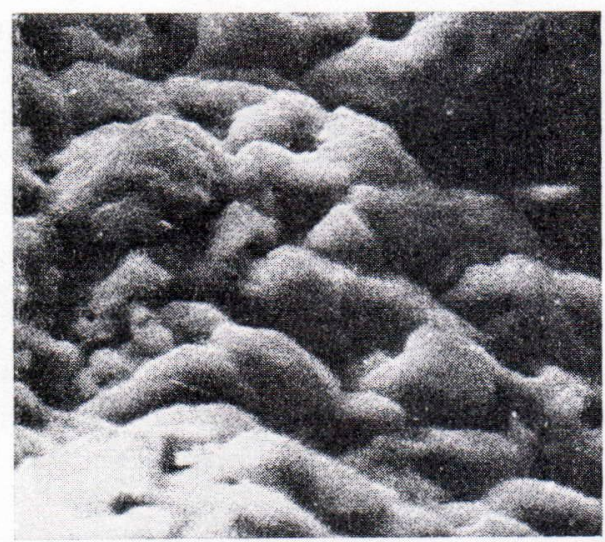

FIG. 3. Very irregular »knoppy» nickelhexahydrite surface. (3700X).

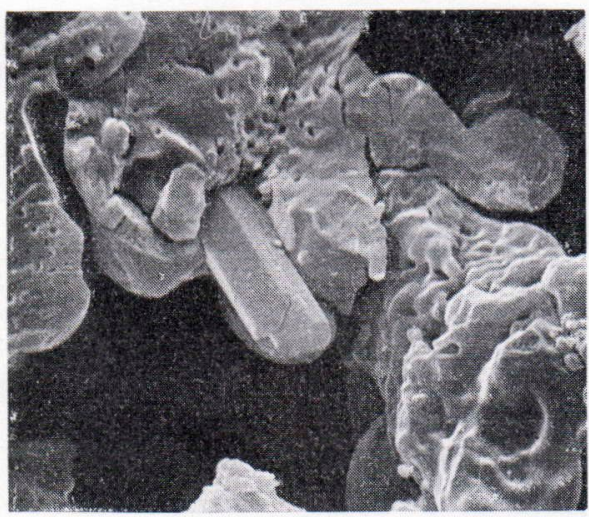

FIG. 5. Two intergrown crystals of an unknown mineral developed in a cavity of nickelhexahydrite. (1650X)

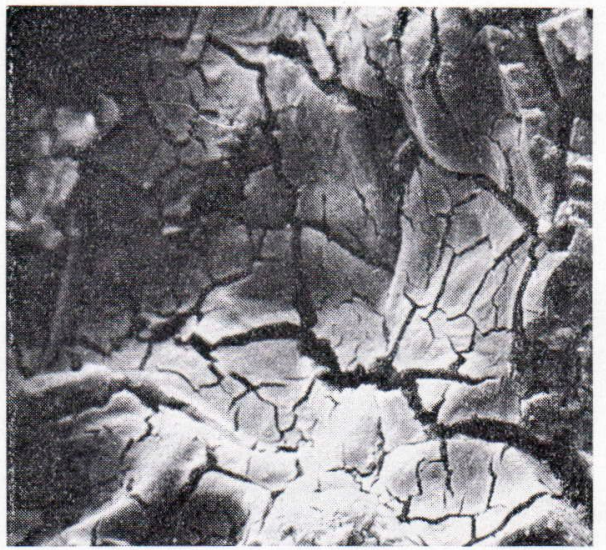

FIG. 2. Rather smooth surface of nickelhexahydrite. Fine cracks may have developed due to dehydration. (1120X).

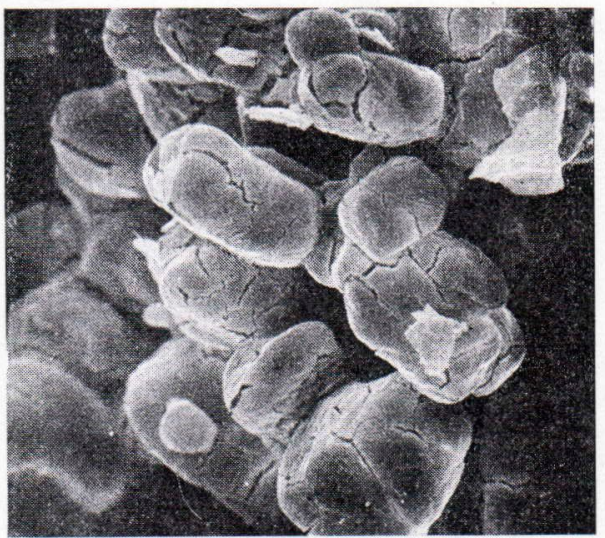

Fig. 4 Aggregate of nickelhexahydrite crystals, each characterized by rounded and poorly defined crystal faces. Cracks, possibly developed as a result of dehydration, resemble those shown in Fig. 2. (2400X).

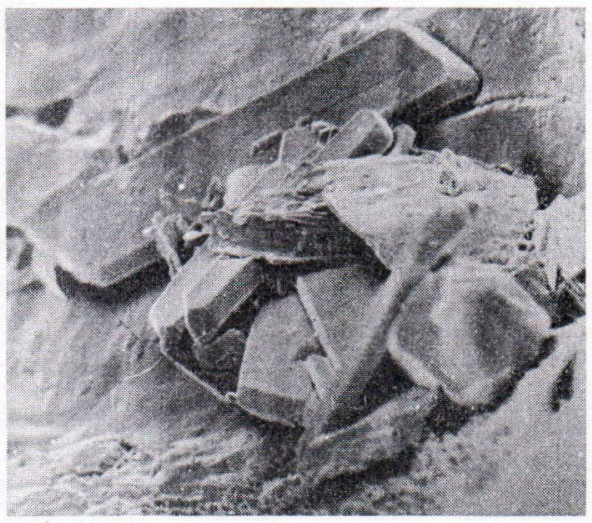

FrG. 6. Crystals of the unknown mineral, ecah bounded by very regularly shaped faces, occur on the rather smooth surface of nickelhexahydrite. ( $2400 \mathrm{X}$ ). 


\section{Morphological description}

In general the nickelhexahydrite crust on the talc is only a few millimeters thick and rather compact. However, locally it may reach a thickness of two to three centimeters in which case the material is extremely porous and fragile (Fig. 1). Small talc fragments often occur imbedded in this material.

When studied by electron microscope, the irregular, porous crust visible in Fig. 1 appears as shown in the photographs in Figs. 2, 3 and 5. The photograph in Fig. 4 may represent an aggregate of nickelhexahydrite crystals, each of which is bounded by poorly defined, rounded crystal faces. The crystals as well as the nickelhexahydrite material shown in Fig. 2 are cut by irregular fractures whose shape suggests that they developed as a result of shrinkage, possibly due to dehydration of the mineral. Such a process could have taken place when the mineral was exposed to hot, sunny weather conditions.

Rare idiomorphic crystals of an unidentified mineral have developed in cavities (Fig. 5) or simply upon rather smooth-surfaced nickelhexahydrite (Fig. 6). The crystals are defined by well developed faces. A $\beta$-angle of approximately $113^{\circ}$, representing the angle between the prismatic and the basal directions, can be measured on photographs of the crystals. This angle differs considerably from that of the nickelhexahydrite, which is close to $98^{\circ}$ (Table 2). On basis of the morphological measurements the mineral may possibly be gypsum.

\section{Chemistry}

Spectrographic analyses (Table 1) gave the content of the minor elements dissolved in the nickelhexahydrite lattice. (The unidentified mineral, Figs. 5 and 6 , is present in amounts too small to influence the analytical results, whatever the composition of the mineral may be). Two analyses of nickelhexahydrite from Norilsk have been published by Oleinikov et. al. (1965). It is

\section{TABLE 1}

Spectrographic analyses of minor elements contained in the nickelhexahydrite from Lahnaslampi in Finland. A large Hilger quartz spectrograph was used. The investigated material was mixed with carbon and strontium carbonate, the latter as an internal standard in the following proportions: Spl.: $\mathrm{SrCO}_{3}: \mathrm{C}=1: 1: 4$. The standards used were synthetic and natural silicates.

$\begin{array}{lll}\mathrm{Mg} . & : 3 \quad \text { percent } \\ \mathrm{Fe} & : 3 \\ \mathrm{Mn} & : 0.3 \\ \mathrm{Ca} & : 0.3 \quad \\ \mathrm{Co} & : 0.1 \\ \mathrm{Cu} & : 0.004 \\ \mathrm{Si} & : \text { tr.. }\end{array}$

$\mathrm{Pb}, \mathrm{Zn}$ and $\mathrm{Al}$ : not detected

characterized by rather similar amounts of magnesium, iron and cobalt but much more copper ( 0.7 to 2.3 percent) and smaller amounts of manganese ( 0.7 percent) compared with the Lahnaslampi mineral. None of the other elements listed in Table 1 were detected by Oleinikov et. al. (1965). The calcium content listed in the table could possibly originate from the very small amounts of calcite associated with the nickelhexahydrite, although its presence could not be confirmed by electron microscope examination or by $\mathrm{X}$-ray investigation.

\section{X-ray crystallography}

Nickelhexahydrite belongs to the same family of minerals as hexahydrite $\left(\mathrm{MgSO}_{4} \cdot 6 \mathrm{H}_{2} \mathrm{O}\right)$, moorhouseite $\left(\mathrm{Co}(\mathrm{Ni}, \mathrm{Fe}, \mathrm{Mn}) \mathrm{SO}_{4} \cdot 6 \mathrm{H}_{2} \mathrm{O}\right)$ and bianchite $\left.(\mathrm{Zn}, \mathrm{Fe}) \mathrm{SO}_{4} \cdot 6 \mathrm{H}_{2} \mathrm{O}\right)$. The cell di-

\section{TABLE 2}

Cell dimensions of hexahydrite (1), moorhouseite (2) nickelhexahydrite ( 3 and 4 ). 1 and 2 are taken from Strunz (1970), 3 from Sutor (1959) and 4 is based on guinier film 1955 on material from Lahnaslampi in Finland.

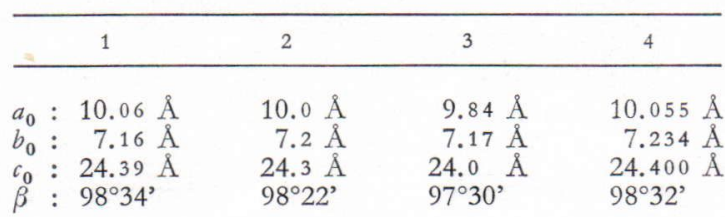


mensions of the three minerals (Table 2) are very similar, almost identical (Strunz, 1970). The cell dimensions of synthetic nickelhexahydrite, determined by Sutor (1959) and reproduced by Strunz (1970), are also listed. Oleinikov et al. (1965) did not give any cell dimensions for the natural nickelhexahydrite from Norilsk. The values $\mathrm{a}_{0}$ and $\beta$ of the synthetic compound vary significantly from those of hexahydrite and moorhouseite. The cell dimensions of the Finnish nickelhexahydrite are based upon a guinier powder film with very sharp lines (guinier film No. 1955). Consequently, the cell dimensions of the Finnish nickelhexahydrite listed in Table 2, excluding those given by Sutor (1959), are considered representative of the mineral.

Acknowledgement - The author is grateful to Mrs. H. Bollingberg for performing the spectrographic analyses and to Mr. E. Leonardsen who helped with the X-ray investigations.

\section{REFERENCES}

Oleinikov, B. V., Shvartzev, S. L., Mandrikova, N. T. and Oleinikova, N. N. (1965). The new mineral nickelhexahydrite. Zapiski, Vses. Mineral. Obschch, 94, $534-47$.

Strunz, O. (1970). Mineralogische Tabellen. Berlin.
Sutor, D. J. (1959). The unit cell dimensions and space group of monoclinic $\mathrm{NiSO}_{4} \cdot 6 \mathrm{H}_{2} \mathrm{O}$. Acta Cryst., 12,72 .

Manuscript received, February 9, 1973. 